\title{
A Case Study of Convergence Classes for Improving Capability of Achievement Motivation and Attitudes toward Acceptance of Disabilities in University Students: Focusing on the Prospective Audiologists, General Teachers, Special Education Teachers and Social Service Workers
}

\author{
Soo Jin $\mathrm{Cho}^{1}$, Eun Kyo Ko ${ }^{2}$ \\ 'Departments of Speech-Language Pathology \& Audiology, ${ }^{2}$ Social Welfare, Nambu University, Gwangju, Korea
}

대학생들의 성취동기역량과 장애수용태도 향상을 위한 융복합 수업 사례:

예비 청능사, 일반교사, 특수교사 및 사회복지사를 대상으로

$$
\text { 조 수 진 } \cdot \text { 고 은 교 }{ }^{2}
$$

남부대학교 언어치료청각학과 ${ }^{1}$, 사회복지학과 ${ }^{2}$

\begin{abstract}
Purpose: This research aimed to identify the effects of convergence education and suggest the basic data to nurture innovative and collaborative human resources by analyzing the differences of the achievement motivation capability and the attitudes toward acceptance of disabilities of university students between before and after the convergence classes under the title of 'Understanding Children with Disabilities'. Methods: The subjects are 127 second year students in five departments regarding integrated education of children with and without disabilities (department of speech-language pathology and audiology; early childhood education; early childhood special education; elementary special education; and social welfare) of $\mathrm{N}$ University located in $\mathrm{G}$ city. The classes were given in the form of textbook-based curriculum, field trainings (volunteer activities related to the improvement of awareness of disabilities and human rights of people with disabilities) and special lectures by invited experts by sufficiently reflecting the core principles (autonomy, bridgeability, contextuality and diversity) of convergence education. Results: As a result of analysis, the score after the convergence class of achievement motivation capability and attitudes toward the acceptance of disabilities of the university students was higher than the score of the test before the class, having statistically significant differences. Conclusion: This study holds significance as it discovered that the convergence class of 'Understanding of Children with Disabilities' is a curriculum subject to improve achievement motivation capability and attitudes toward the acceptance of disabilities of the university students, who are the prospective specialists in education, rehabilitation and welfare of people with disabilities.
\end{abstract}

Key Words: Achievement motivation capability, Attitudes toward the acceptance of disabilities, Convergence classes.

Received: October 9, 2015 / Revised: November 23, 2015 / Accepted: December 5, 2015

Correspondence: Eun Kyo Ko, Department of Social Welfare, Nambu University, 23 Cheomdanjungang-ro, Gwangsan-gu, Gwangju 62271, Korea Tel: +82-62-970-0133 / Fax: +82-62-970-0496 / E-mail: silver2419@nambu.ac.kr 


\section{INTRODUCTION}

과학 기술의 발전과 변화의 흐름 속에 현대 사회는 다학문적 협력을 통하여 상생할 수 있는 새로운 방안을 모색하고 있다. 그 흐름이 사회, 경제, 과학 기술 등의 분야에서 뿐만 아니라 교 육 현장에서도 강조되기 시작하였다. 이러한 시대적 요구에 따 라 어느 한 분야의 전문가보다는 다양한 영역을 넘나들며, 기 존 지식들을 융합하여 새로운 지식을 창조할 수 있는 '융복합 (convergence)'형 인재 양성을 목표로 한 학문 간의 교류가 활 발히 이루어지고 있다(You, 2014).

여기서 '융복합'이라는 용어는 '통합(integration)', '융합(fusion), '통섭(consilience)' 등의 다양한 용어와 혼용되고 있는 데, 일반적으로 학문 간의 '통합'은 각 영역의 학문적 특징은 유 지한 채 관심 있는 영역을 서로 공유하는 일종의 물리적인 결 합 형태로 주제나 교과 영역 간의 연계체제를 추구하는 방식이 다. '융합'은 각 학문의 지식과 특징을 녹여 새로운 학문 영역을 구축한다는 의미의 화학적인 결합 형태를 의미한다. 또한 '통섭' 은 분과 학문의 장벽을 넘어서 각 학문의 지식을 생물학적인 결합 형태로 통합하는 고차원적 통합을 의미하는데(Park, 2015), 현대 사회에서는 각 영역 간의 경계가 허물어지는 차원 을 넘어 학문 간의 수준, 방법 및 구성을 중요한 요소로 보고 통합, 융합, 통섭 등의 의미를 포괄하는 융복합이라는 용어의 사용이 더 보편적이라는 의견이다(Ju et al., 2012).

이러한 융복합형 인재 양성을 위한 교육에 대해 합의된 학문 적 개념은 아직 명확히 밝혀진 바 없지만, $\operatorname{Kim}(2014)$ 은 '학문 또는 교과로 대표되는 각 분야의 경계를 허무는 방식을 통해 새로운 지적 성과를 추구하는 교육이라고 정의내린 반면, $\mathrm{Ham}$ et al.(2013)은 '교과 내·외적 주제나 개념을 중심으로 관련성이 있는 교과들의 학습 요소를 실세계 맥락과 연결된 학습 활동을 통해서 학생들 스스로 탐구하고 표현할 수 있는 학습 경험을 제공하는 교육'이라고 개념화하기도 하였다. 한편 Cha et al. (2014)은 융복합 교육의 개념적 특징을 크게 4가지로 구분하여 다음과 같은 ' $\mathrm{ABCD}$ 모델로 설명하였다. 첫째, 교수·학습에 참 여하는 구성원들의 자율적 참여를 기반으로 하는 자율성(autonomy)이다. 이는 수업에 참여하는 학습자의 관점에서 스스 로 학습 내용이나 방식을 선택할 수 있도록 함으로써 수업에 대한 성취도를 높이고 동기부여를 가능하게 하며, 교수자에게 는 교수 활동의 자율권을 보장함으로써 학습 목표나 교수·학 습 방법을 자유롭게 구성할 수 있도록 하는 것이다. 둘째, 교 수·학습을 구성하는 요소 간의 관련성인 연계성(bridgeability)은 협동학습이나 소그룹 활동 및 의사소통을 강조한 학습 을 의미한다. 특히 구성원 간의 연계성은 학습자 간의 상호작 용을 통하여 사회적인 관계를 형성할 수 있고, 타인을 이해하
는데 효과적이다. 셋째, 학생들의 실제 삶과 관련한 맥락을 고 려한 교수·학습의 가능성인 맥락성(contextuality)은 학습자에 게 실생활적 맥락이나 유의미한 내용으로 구성된 과제를 제시 함으로써 다양한 문제 상황에 능동적으로 대처할 수 있는 능 력을 함양하도록 하는 것이다. 넷째, 교수·학습에 참여하는 구 성원들의 문화적·인식론적 다양성(diversity)을 이해하고 존중 하는 과정을 통해서 협력적 관계를 구성하도록 하는 것이다.

장애인들의 정상화(normalization)와 통합화라는 시대적 요 구에 맞춰 볼 때 그들의 성공적인 삶을 위해서는 교육, 재활, 복 지 및 상담 등이 다차원적이고 포괄적으로 지원되어야 하기 때 문에 전문화된 융복합형 인재양성의 필요성으로 이어지고 있 어 전문화된 인적 네트워크를 바탕으로 지역 사회와의 연계를 통한 원활한 협력적 팀 접근(collaborative team approach)의 중요성이 강조되어 왔다(Kang \& Park, 2006; Utley \& Rapport, 2002). 하지만 다양한 분야의 전문가들은 장애인에 대한 올바른 인식과 수용태도 및 타 분야에 대한 이해 부족으로 원 활한 협력적 팀 접근을 시행하지 못하고 있는 실정이다. 특히 장애인에 대한 인식과 수용태도는 고정적인 것이 아니라, 새로 운 지식이나 경험 및 정보를 습득함으로써 지속적으로 변할 수 있기 때문에 교사를 포함한 관련 분야의 전문가나 비장애인들 에게 인간의 보편적 개별화라는 측면뿐만 아니라 장애로 인한 개인의 차이와 다양성을 올바르게 이해하고 수용할 수 있는 다 각적이고 구조화된 교육적 개입이 필요하다(Jung, 2010).

최근 들어 한국 사회가 지식정보화 사회를 선도하면서 가치 있는 정보를 소유하는 것이 사람들의 능력을 판단하고 평가하 는 기준이 되면서 교육 현장에서는 기존의 '지식(knowledge)'을 학습하는 것에서 나아가 문제해결역량, 리더십역량, 자아역량 및 성취동기역량 등 잠재되어 있는 학생들의 다양한 '능력 (competence)'을 발휘할 수 있는 교육적 패러다임의 전환이 곧 개인과 국가의 경쟁력을 결정한다는 견해가 나타나기 시작하였 다(Kim, 2015a). 특히 학생들의 학업성취나 진로 및 다양한 활 동능력을 결정짓는 요인 중 가장 중요한 요소가 성취동기역량 이라고 밝혀지면서 학습동기유발을 통해 학생들의 성취동기역 량을 향상시키고자 하는 다양한 프로그램들이 보급되고 있다. 그러나 관련 선행연구들은 초·중·고등학생들을 대상으로 한 경우가 대부분이며(Geum, 2006; Kim, 2008), 특정 영역으로 의 진출을 앞둔 대학생을 대상으로 한 연구는 매우 미흡하다.

현재 교육·재활·복지 분야에서는 장애인 및 비장애인의 생 애주기적 발달특성에 기반한 종합적서비스 이해능력이 높은 전문 인력의 양성을 요구하고 있다. 또한 관련 전공학과 졸업생 들의 진로 역시 자신의 주 전공 분야뿐만 아니라, 전공과 성격 이 비슷한 유사 영역으로도 확대되고 있으므로 이를 위해 장 애관련 전문지식의 함양과 장애에 대한 올바른 이해 및 전공 
학문 간의 융복합적 접근을 통한 포괄적인 장애인 서비스 지원 을 고려해야 할 시점이다. 따라서 대학생의 장애수용태도의 수 준을 향상시켜 서비스 대상에 대한 이해를 높이고, 대학생들의 학업성취능력, 진로역량, 성취동기역량 등 다양한 활동능력을 향상시킬 수 있는 교육 프로그램 개발이 필요하다.

이에 본 사례에서는 장애아동을 위한 교육·재활·복지 분야 의 융복합형 인재 양성을 목표로 대학생들의 성취동기역량과 장애수용태도를 향상시키기 위하여 관련 전공학과(언어치료청 각학과, 유아교육과, 유아특수교육과, 초등특수교육과, 사회복 지학과) 재학생들을 대상으로 진행한 '장애아동의 이해' 교과 목에 대한 융복합 수업을 고찰해봄으로써 예비 청능사, 일반교 사, 특수교사 및 사회복지사의 성취동기역량과 장애수용태도 에 미치는 효과를 규명하고, 그에 따른 융복합 교육의 의의에 대해서 살펴보고자 하였다.

\section{MATERIALS AND METHODS}

\section{연구대상}

본 사례는 $\mathrm{G}$ 시에 위치한 $\mathrm{N}$ 대학교의 학과 중 장애 아동과 비 장애 아동을 위한 통합교육 개입이 가능한 5 개 학과(언어치료 청각학과 28명, 유아교육과 28명, 유아특수교육과 15명, 초등특 수교육과 27명, 사회복지학과 29명)에 재학 중인 2학년 127 명을 대상으로 하였다.

\section{연구 방법 및 절차}

본 사례는 융복합 교육의 핵심원리인 $\mathrm{ABCD}$ 모델(Cha et al., 2014)을 근거하여 수업 프로그램을 구성한 후 2015년 3월 2일 부터 6월 19일까지 총 15주 동안 '장애아동의 이해' 교과목을 융복합 교육의 형태로 진행하였다. 프로그램의 구체적인 구성 내용은 다음과 같다. 첫째, 교수·학습에 참여하는 구성원들의 '자율성'을 높이기 위하여 매주 이론 강의 2시간과 소그룹 활동 1 시간의 수업으로 교수 방법을 다양화하였고, 전문가 초청 특 강 1 회와 현장학습(장애인식개선 및 장애인권교육을 위한 봉 사활동) 2 회를 수업 시간에 포함시켜 수업 상황에 대한 변화를 유도함으로써 교수자의 자율성을 확보하였다. 또한 소그룹 활 동 시간에는 5 개 학과의 학생이 1 명 이상씩 포함된 모둠을 조직 하여 자율적인 토론 및 참여를 통해 자기주도적 학습이 이루어 질 수 있도록 함으로써 타 전공학문의 지식을 공유할 수 있도 록 융복합 수업모형을 고려하였다. 둘째, 장애아동 관련 교육. 재활 - 복지 분야 교과에 대한 학문 간의 연계와 의사소통을 강 조한 소그룹 활동이나 현장학습을 통해 교수·학습을 구성하 는 요소 간의 '연계성'을 확보하였다. 셋째, 수업에 참여하는 대 학생들이 일반 유치원생 및 초등학교 학생들을 대상으로 하는
장애인식개선 및 장애인권교육 프로그램의 교육자로서 프로그 램 내용의 기획, 제작 및 진행에 참여할 수 있는 현장학습의 기 회를 제공함으로써 학생들이 자신과 관련 있는 의미 있는 문제 와 맥락을 경험하고 해결하는 과정에서 융복합 교육의 '맥락성' 을 학습할 수 있도록 유도하였다. 넷째, 장애아동에 대한 이해 를 바탕으로 관련 5 개 전공 간의 교류와 포괄적 장애인 서비스 지원에 대한 이해를 넓히고 다양한 협력적 과제를 수행할 수 있도록 함으로써 교수·학습에 참여하는 구성원들의 문화적. 인식론적 '다양성'을 이해하고 서로 존중할 수 있도록 하였다. 또한 '장애아동의 이해' 교과목의 교육과정은 교육·재활·복지 분야 전공 교수 5 인의 자문을 바탕으로 장애아동에 대한 이해, 장애유형별(정신지체, 학습장애, 자폐성장애, 정서·행동장애, 시각장애, 청각장애, 의사소통장애, 건강장애 및 발달지체) 특 성, 교육, 재활, 복지, 및 문제행동 지원방법 등 장애아동의 전반 적인 내용을 습득할 수 있도록 구성함으로써 장애아동에 대한 전문지식을 포괄적으로 이해할 수 있도록 하였다(Figure 1). 이 와 같이 융복합 수업의 전체적인 프로그램을 완성한 후, 교육. 재활- 복지 분야 교수 3 인과 박사 학위를 소지한 통합교육현장 전문가 2인에게 융복합 교육의 원리에 따른 수업 내용의 타당 도를 검증받았다.

특히 현장학습 시간에는 $\mathrm{G}$ 시 S보건지소와 연계하여 초등학 교 3곳과 유치원 2곳의 일반 학생들을 대상으로 시행한 '장애 인식개선 및 장애인권교육 프로그램에 본 수업 대상자들을 교 육자로 참여시켜 비장애 학생들에게 장애에 대한 다양성을 인 간 중심에서 이해할 수 있는 기회를 제공하였다. 본 프로그램 은 '장애인식개선 및 장애인권교육' 프로그램은 장애인권교육 팀, 인형극팀, 장애체험팀 등 3개 팀으로 나누어 진행되었다. 이 중 장애인권교육은 이론 강의로 $\mathrm{G}$ 시 $\mathrm{N}$ 장애인자립생활지원센 터의 장애인 참여자가 재능기부 하였다. 인형극팀은 유아교육 과 학생들이 중심이 되어 청각장애아동을 주제로 한 동화책 2 권[넌 왜 보청기를 하니(Kim, 2006)], [내 귀는 짝짝이(Rideau, 1999)]의 내용을 각색하여 '내 귀는 짝짝이'라는 인형극의 대본 과 무대배경을 직접 준비하였으며, 완성된 대본은 인형극에 출 연하는 여학생들의 음성으로 N대학교 음악학과 녹음실에서 Nuendo 6 프로그램(Steinberg Inc., Hamburg, Germany)으로 녹음한 후 사용하였다. 장애체험팀에는 언어치료청각학과, 사 회복지학과, 유아특수교육과, 초등특수교육과 학생들이 중심 이 되어 다양한 보조공학기기(노인 체험복, 흰 지팡이, 휠체어, 확대경 등)를 이용하여 장애체험활동(노인 체험, 장애릴레이 경 기, 확대단어 찾기, 흰 지팡이 사용하여 학교 탐방하기, 방과 방 사이, 종이컵 전화기 등)의 기획, 제작 및 진행에 참여하였으며, 일반 초등학생들과 유치원 학생들이 장애에 대한 거부감을 없 애고 긍정적인 이해를 할 수 있도록 하였다(Figure 2). 


\begin{tabular}{|c|c|c|c|}
\hline Weeks & Subject & Course contents & Small group activities \\
\hline \multirow[b]{2}{*}{1} & \multirow[b]{2}{*}{$\begin{array}{l}\text { Understanding children with } \\
\text { disabilities }\end{array}$} & \multirow{2}{*}{$\begin{array}{l}\text { - Understanding special education and development } \\
\text { rehabilitation services } \\
\text { - Understanding the law related to children with } \\
\text { disabilities }\end{array}$} & \multirow[b]{2}{*}{$\begin{array}{l}\text { - Creating small groups } \\
\text { - Introducing majors by department }\end{array}$} \\
\hline & & & \\
\hline 2 & Special education method & $\begin{array}{l}\text { - Individualized education plan, special } \\
\text { education technology devices } \\
\text { - Welfare of disabled children (transition education, } \\
\text { vocational education) }\end{array}$ & $\begin{array}{l}\text { - Assistive technology devices } \\
\text { experience }\end{array}$ \\
\hline 3 & $\begin{array}{l}\text { Special education } \\
\text { Supports for children } \\
\text { with problem behaviors }\end{array}$ & $\begin{array}{l}\text { - Understanding and supporting deviant behavior } \\
\text { - Positive behavior support }\end{array}$ & $\begin{array}{l}\text { - Sharing the cases of children } \\
\text { with problem beshavior }\end{array}$ \\
\hline 4 & Intellectual disability & \multirow{4}{*}{$\begin{array}{l}\text { - Definition, causes and classification of disabilities } \\
\text { - Diagnosis and evaluation of disabilities } \\
\text { - Education and rehabilitation strategies of children } \\
\text { with disabilities }\end{array}$} & $\begin{array}{l}\text { - Awareness of children with } \\
\text { disabilities }\end{array}$ \\
\hline 5 & Learning disability & & - Sharing experience of disability \\
\hline 6 & Autistic spectrum disorder & & - Planning of field trip \\
\hline 7 & Health impairment & & - Making materials for field trip I \\
\hline 8 & $\begin{array}{l}\text { Small group discussion } \\
\text { \& midterm exam }\end{array}$ & \multicolumn{2}{|c|}{$\begin{array}{l}\text { - Discussion on acceptance attitudes toward children with disability \& submitting group assignment } \\
\text { - Midterm exam: multiple choice \& short answer questions }\end{array}$} \\
\hline 9 & Communication disorders & \multirow{3}{*}{$\begin{array}{l}\text { - Definition, causes and classification of disabilities } \\
\text { - Diagnosis and evaluation of disabilities } \\
\text { - Education and rehabilitation strategies of children } \\
\text { with disabilities }\end{array}$} & - Making materials for field trip II \\
\hline 10 & Hearing impairment & & - Field trip rehearsal I \\
\hline 11 & Visual impairment & & - Field trip rehearsal II \\
\hline 12 & Field trip I & \multicolumn{2}{|c|}{$\begin{array}{l}\text { - Volunteer activities for improving disability awareness and disability rights education } \\
\text { at two elementary schools in G city }\end{array}$} \\
\hline 13 & Invited expert lecture & \multicolumn{2}{|c|}{ - Characteristics and cases by each emotional and behavioral disorder type } \\
\hline 14 & Field trip II & $\begin{array}{l}\text { - Volunteer activities for improving disability awaren } \\
\text { at one elementary school and two kindergartens in }\end{array}$ & ability rights education \\
\hline 15 & $\begin{array}{l}\text { Comprehensive } \\
\text { summary \& final exam }\end{array}$ & $\begin{array}{l}\text { - Comprehensive summary of the lectures } \\
\text { - Final exam: multiple choice \& short answer questio }\end{array}$ & \\
\hline
\end{tabular}

Figure 1. Weekly curriculum and small group activities.

Figure 2. Signboard examples for learning activities of experience of disabilities.
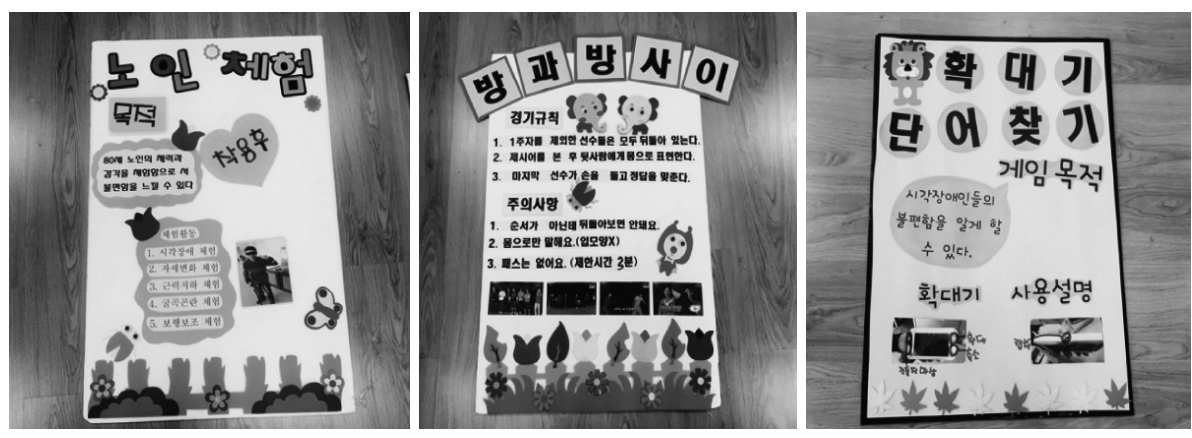


\section{연구 도구}

\section{성취동기역량}

본 사례에서는 대학생의 성취동기역량을 측정하기 위하여 선행연구(Kwon \& Kim, 2010; Kim, 2015a)에서 사용한 설문 지를 바탕으로 동기유발, 성취지향성 및 학습실행력의 3 가지 하위 요인에 해당하는 문항에 대하여 '전혀 아니다'를 1점, '보통 이다를 3점, '매우 그렇다'를 5점으로 하는 Likert 5점 형식의 등간 척도를 사용하였다.

3 가지 하위 요인을 구체적으로 살펴보면, '동기유발'은 행동 을 유발하고 어떤 목적을 위하여 방향을 설정한 후, 지속하고 자 하는 내적상태로 능동적이고 주도적으로 학습을 완성해 나 가도록 하는 과정을 의미하며 "모르는 사람이나 일 등을 서로 알아가는 재미 때문에 어느 것이든 참여한다'를 포함한 20 문항 이다. '성취지향성'은 개인이 구체적인 목표를 설정한 후, 그 목 표를 성취하도록 방향성을 제시하고 지속적인 행동을 유도하 는 힘을 의미하며 '해야 할 일을 성취하였을 때 느끼는 만족감 을 얻기 위해 일을 한다를 포함한 14문항이다. '학습실행력'은 학습 욕구, 태도 및 자기 주도적 능력에 대해 스스로 부족한 부 분을 보완하여 계획적인 학습관리능력을 기초로 학습을 이행 하고자 하는 능력을 의미하며 "나는 남보다 더 과제를 잘 수행 할 수 있다고 생각한다를 포함한 20문항이다. 각 문항은 점수 가 높을수록 성취동기역량이 높다는 것을 의미하며, 설문지의 구성 및 신뢰도 Cronbach alpha 계수는 Table 1과 같다.

\section{장애수용태도}

본 사례에서는 대학생들의 장애수용태도를 측정하기 위하여 Lee(2011)가 번안하고 사용한 장애태도요인 척도(Disability Factor Scales)를 수정·보완하여 사용하였다. 이 연구 도구는 인구사회학적 항목을 제외한 장애인에 대한 태도에 관한 설문 지로 무조건적인 거부, 추론된 정서장애, 손상을 입지 않은 타 기능의 제한요인, 친교의 거부 및 접촉 시 긴장 등 5 개의 하위 요인으로 구성되어 있다. 인구사회학적 4문항을 포함하여 무조 건적인 거부는 '장애인들은 특정한 지역사회에서 그들끼리 모 여 살아야 한다'를 포함한 4문항, 추론된 정서장애는 '장애인들 은 비장애인과 어울리는 데 있어서 매우 소극적이다를 포함한

Table 1. Questionnaire items and reliability for achievement motivation capability

\begin{tabular}{llccc}
\hline \multirow{2}{*}{ Subfactors } & \multirow{2}{*}{$\begin{array}{c}\text { No. of } \\
\text { items }\end{array}$} & \multicolumn{2}{c}{ Reliability } \\
\cline { 3 - 5 } & & Pre-test & Post-test \\
\hline 1 & Motivation & 20 & 0.870 & 0.856 \\
2 & Achievement orientation & 14 & 0.666 & 0.698 \\
3 & Learning execution & 20 & 0.869 & 0.870 \\
\hline
\end{tabular}

7문항, 손상을 입지 않은 타 기능의 제한요인은 ‘손발이 없는 사 람은 의수족으로 일할 수 있으나 업무에 지장을 줄 것이다를 포함한 6 문항, 친교의 거부는 '장애인과 결혼하는 사람들에게 는 반드시 문제가 생길 것이다를 포함한 6문항, 접촉 시 긴장은 ‘장애인이 나와 가까이 있을 때 불쾌감을 느낀다를 포함한 5 문 항 등 부정적인 태도를 의미하는 총 32문항으로 측정하였다. 본 연구의 척도는 '매우 그렇지 않다'를 5점, '보통이다'를 3점, '매우 그렇다'를 1점으로 하는 Likert 5점 형식의 등간 척도를 사용하였다. 각 문항은 점수가 높을수록 태도의 수준이 긍정적 임을 의미한다. 설문지의 구성 및 신뢰도 Cronbach alpha 계수 는 Table 2와 같다.

\section{자료 분석}

본 사례에서는 ‘장애아동의 이해’ 교과목에 대한 융복합 수 업이 대학생들의 성취동기역량과 장애수용태도에 미치는 효과 를 알아보기 위하여 단일집단 사전-사후 설계를 통해서 분석을 시행하였다. 자료 수집은 융복합 수업 실시 이전에 사전검사를, 융복합 수업 종결 후 사후검사를 실시하였으며 사전·사후의 요 인 간 차이 검증은 SPSS WIN 18.0(SPSS Inc., Chicago, IL, $\mathrm{USA}$ )을 이용하여 유의수준 0.05 에서 대응표본 $t$-검증(paired sample $t$-test)으로 분석하였다.

\section{RESULTS}

\section{대학생들의 성취동기역량}

'장애아동의 이해' 교과목의 융복합 수업 전·후 대학생들의 성취동기역량에 대한 차이를 분석한 결과, 사전검사에서 점수 가 가장 높은 요인은 성취지향성으로 평균 3.64( \pm 0.993)점이 었으며 사후검사에서는 동기유발 요인이 평균 3.96 $( \pm$ 0.857)점 으로 가장 높게 나타났다. 사전·사후 검사의 요인 간 차이에서 는 동기유발 $(t=-14.729)$, 성취지향성 $(t=-6.261)$ 및 학습실행 성 $(t=-13.627)$ 의 모든 하위 요인에서 사후검사 점수가 더 높게 나타났으며, 통계적으로 유의한 차이를 보였다 $(p<0.05)$ (Table 3). 이는 '장애아동의 이해' 교과목의 융복합 수업이 대학생의

Table 2. Questionnaire items and reliability for the attitudes toward acceptance of disabilities

\begin{tabular}{llccc}
\hline \multirow{2}{*}{ Subfactors } & \multirow{2}{*}{$\begin{array}{c}\text { No. of } \\
\text { items }\end{array}$} & \multicolumn{2}{c}{ Reliability } \\
\cline { 3 - 5 } & & Pre-test & Post-test \\
\hline 1 Generalized rejection & 4 & 0.723 & 0.694 \\
2 Inferred emotional consequences & 7 & 0.788 & 0.767 \\
3 Imputed functional limitation & 6 & 0.613 & 0.686 \\
4 Rejection of intimacy & 6 & 0.780 & 0.689 \\
5 Interaction strain & 5 & 0.744 & 0.666 \\
\hline
\end{tabular}


Table 3. Results of paired $t$-test on achievement motivation capability

\begin{tabular}{lccc}
\hline Subfactors & M & SD & $t$ \\
\hline Motivation & & & \\
$\quad$ Pre-test & 3.34 & 0.903 & $-14.729^{* * *}$ \\
$\quad$ Post-test & 3.96 & 0.857 & \\
Achievement orientation & & & \\
$\quad$ Pre-test & 3.64 & 0.993 & $-6.261^{* * *}$ \\
$\quad$ Post-test & 3.92 & 0.720 & \\
Learning execution & & & \\
$\quad$ Pre-test & 3.43 & 0.977 & $-13.627^{* * *}$ \\
$\quad$ Post-test & 3.94 & 0.853 & \\
\hline
\end{tabular}

${ }^{* * *} p<0.001$. M: mean, SD: standard deviation

Table 4. Results of paired $t$-test on the attitudes toward acceptance of disabilities

\begin{tabular}{lccc}
\hline Subfactors & $\mathrm{M}$ & $\mathrm{SD}$ & $t$ \\
\hline Generalized rejection & & & \\
$\quad$ Pre-test & 4.13 & 0.726 & $-4.955^{* * *}$ \\
$\quad$ Post-test & 4.37 & 0.534 & \\
Inferred emotional consequences & & & \\
$\quad$ Pre-test & 3.79 & 0.721 & $-5.679^{* * *}$ \\
$\quad$ Post-test & 4.05 & 0.626 & \\
Imputed functional limitation & & & \\
$\quad$ Pre-test & 3.66 & 0.571 & $-5.709^{* * *}$ \\
$\quad$ Post-test & 3.92 & 0.540 & \\
Rejection of intimacy & & & \\
$\quad$ Pre-test & 3.73 & 0.682 & $-5.071^{* * *}$ \\
$\quad$ Post-test & 3.94 & 0.554 & \\
Interaction strain & & & \\
$\quad$ Pre-test & 4.15 & 0.687 & $-5.463^{* * *}$ \\
$\quad$ Post-test & 4.39 & 0.509 & \\
\hline
\end{tabular}

${ }^{* * *} p<0.001$. M: mean, SD: standard deviation

성취동기역량에 긍정적인 효과가 있다는 것을 의미한다.

\section{대학생들의 장애수용태도}

'장애아동의 이해' 교과목의 융복합 수업 전·후 대학생들의 장애수용태도에 대한 차이를 분석한 결과, 사전·사후 검사에서 점수가 가장 높은 요인은 모두 접촉 시 긴장으로 각각 평균 4.15 $( \pm$ 0.687)점과 4.39( \pm 0.509)점이었다. 사전·사후 검사의 요인 간 차이에서는 무조건적인 거부 $(t=-4.955)$, 추론된 정서장애 $(t$ $=-5.679)$, 손상을 입지 않은 타 기능의 제한 $(t=-5.709)$, 친교의 거부 $(t=-5.071)$, 접촉 시 긴장 $(t=-5.463)$ 의 모든 하위 요인에서 사후검사 점수가 더 높게 나타났으며 통계적으로 유의한 차이 를 나타내었다 $(p<0.05)$ (Table 4). 이는 '장애아동의 이해' 교 과목의 융복합 수업이 대학생의 장애인식태도에 긍정적인 효과 가 있다는 것을 의미한다.

\section{DISCUSSIONS}

본 사례는 '장애아동의 이해' 교과목에 대한 융복합 수업이 대학생들의 성취동기역량과 장애수용태도에 미치는 영향을 살 펴봄으로써 융복합 수업의 효과와 그 의미를 살펴보고자 하였 으며, 구체적인 논의 내용은 다음과 같다.

첫째, 서론에서도 언급한 바와 같이 최근 사회적으로 융복합 학문에 대한 관심이 증대되고 있는 가운데 대학을 포함한 다 양한 교육현장에서도 사회 변화에 적합한 학업성취, 학습역량 및 성취동기역량 등을 개발할 수 있도록 문학, 수학, 미술 및 무 용 등 다양한 교육과정에서 융복합 수업이 시도되고 있으며, 그 효과를 분석하고자 하는 연구들이 진행되어 왔다(Kim, 2014; Kim, 2015b; Park, 2015; Jung, 2011). 대부분의 융복합 교육은 교과 간의 내용적인 융합을 강조하였던 통합교육이나 비롯한 많은 선진 국가에서 시행하고 있는 과학적 인재양성을 위한 융합인재교육과는 달리 교수 및 학습자, 수업 내용, 교수 방법 등의 교수·학습을 구성하는 요소 간의 자율성, 연계성, 맥락성, 다양성이라는 개념적 특징을 강조하면서 기존 교육과 의 차별성을 갖는다. 이는 학생들의 관심사나 흥미뿐만 아니라 그들에게 의미 있는 지식과 경험을 전달할 수 있는 맥락적 과 제 제시가 중요하다는 것을 의미하며, 학생들이 자기 주도적으 로 학습에 참여할 수 있도록 학생과 학생, 학생과 교수자 간의 협력적 관계를 바탕으로 하는 교수·학습 방법의 적용이 필요 하다는 입장이다(Park, 2015). 본 수업의 사례에서도 융복합 교 육의 4가지 핵심원리에 근거하여 수업을 구성하였으며, 그중 '연계성'과 '자율성'에 초점을 맞추어 학생들이 주도적으로 소그 룹 활동을 진행하고, 현장학습 프로그램에 대한 기획, 제작 및 진행에 주도적으로 참여할 수 있도록 유도함으로써 융복합 교 육의 효과를 최대화하고자 노력하였다. 이는 기존 강의식 수업 의 경우, 교수자와 학생 간의 연계성이 낮을 수 있고 학생들의 학업이나 학습동기가 저하되어 있는 경우가 많기 때문이다. 다 만, '다양성' 측면에서 기본 교과과정에 대한 수업을 관련 전공 교수 2 인이 진행하여 교수자의 다양성 측면에서 다소 부족하였 고, '자율성' 측면에서 소그룹 활동이나 현장학습에서 학생들 의 주도적인 참여는 유도했지만, 학습 주제 및 봉사활동 분야 에 대한 선정과정에서 학생들의 소극적인 태도로 인하여 교수 자의 의견이 많이 반영되어 학생들의 자율성이 완전히 보장되 지는 않았다. 이는 융복합 수업이 전공 교과목으로 운영되어 교양 교과목에 대한 접근과는 다소 다른 역동성이 원인이 되었 다고 사료된다.

둘째, 성취동기역량은 인간 내면에서 추구하는 기대를 실현 시켜 만족감을 얻음으로써 자신의 가치와 존재를 스스로 인정 하게 하는 실천적 욕구를 나타내는 것으로 최근에는 학생들의 
성취동기역량을 강화하기 위하여 동기유발, 성취지향성 및 학 습실행력의 3 가지 하위 요인으로 구성된 다양한 프로그램이 개발되고 있다. $\operatorname{Kim}(2015 \mathrm{a})$ 은 성취동기가 낮은 중학생들을 대 상으로 성취동기역량의 3가지 하위 요인별로 활동 주제(나의 아 바타 만들기, 미래와 세상을 보는 가치관 찾기, my vision college, 학습 성취를 위한 액션 플랜 등)를 선정하여 프로그램을 시행한 결과, 성취동기역량을 포함한 청소년들의 활동역량에 긍정적인 영향을 미치는 것으로 보고하였다. 이 외에도 진로교 육, 리더십 증진 및 다양한 비교과 과정 프로그램을 통해서 학 생들의 성취동기역량을 향상시키고자 하는 연구가 지속되고 있 다(Ahn, 2011; Jung \& Cho, 2010). 본 연구 결과에서도 '장애 아동의 이해' 교과목에 대한 융복합 수업 프로그램이 학생들의 성취동기역량에 유의한 효과가 있는 것으로 나타났다. 다만, 최 근에 시행되고 있는 대부분의 성취동기역량 프로그램의 경우 초-중·고등학생들을 대상으로 한 방과후 수업이나 비교과 과 정의 일환으로 진행되어 학생들의 적극적인 참여와 자율성을 충분히 부여할 수 있고, 프로그램의 내용 역시 성취동기역량의 요인에 잘 맞게 구성된 반면에 본 연구의 경우는 대학 정규 교 육과정에 따른 융복합 수업의 효과를 학생들의 성취동기역량 측면에서 고찰한 것이므로 성취동기역량 프로그램 자체의 효 과를 검증한 선행연구와는 다소 차이가 있다. 하지만 성취동기 역량 프로그램의 특성상 학생들에게 의미 있는 과제를 제시하 여 스스로 설정한 목표나 진로를 구체화하고 자기주도적인 학 습능력을 향상시킬 수 있는 내용으로 구성되어 있어 본 연구의 융복합 수업의 내용과 상당 부분 부합되는 측면이 있다고 판단 된다.

셋째, 장애인에 대한 우리 사회의 인식과 수용태도가 과거에 비해 긍정적인 방향으로 개선되고 있으나 여전히 그들의 능력 이나 일상생활 전반에 대한 잘못된 선입견이 남아 있다. 다시 말하면 장애에 대한 문제를 사회의 제도나 구조적인 측면에서 이해하지 않고 개인의 문제로만 인식하거나(Koo et al., 2006), 장애의 원인을 비과학적인 논리로 접근하는 경향을 보이고 있 다(Ko, 2009). 최근에는 이러한 사회적 분위기를 반영하여 장 애수용태도와 관련된 연구들이 많이 진행되면서 장애인들에게 서비스를 직접 제공할 전문가들이나 예비 전문가인 대학생들 의 장애수용태도가 서비스의 효율성에 직접적인 영향을 미칠 수 있다고 보고하고 있다(Choi, 2011). 선행연구에 의하면 재활 학이나 특수교육관련 전공 학생들은 타 전공 학생들에 비해서 장애수용태도 점수가 더 높게 나타났으며(Hunt \& Hunt, 2000; Choi et al., 2008), 사회복지학을 전공하고 있는 학생들의 특수 교육 교과목 수강이나 실습 경험이 장애인에 대한 긍정적인 태 도와 관련이 있었고(Lee, 2007), 보건학 전공 대학생들의 장애 수용태도 역시 긍정적이었으며, 특수 교과목 수강이나 통합교
육 경험이 장애수용태도에 유의한 영향을 미치는 것으로 나타 났다(Kim et al., 2015). 이와 같이 특수교육 관련 교과목 수강 경험, 자원봉사의 경험이나 실습 등이 장애수용태도 변화에 중 요한 요인으로 작용할 수 있으므로 관련 전문가들을 포함한 비 장애 아동 및 성인을 대상으로 장애에 관한 수업이나 강의를 통한 정보제공, 장애인과의 접촉을 통한 활동, 장애체험활동, 집단 토의 및 시청각 자료나 동영상 제공 등 다양한 활동으로 구성된 장애인식개선 교육 프로그램을 시행함으로써 장애인에 대한 긍정적인 수용태도를 유도하고 있다(Jung, 2010).

본 연구에서도 교육·재활·복지 분야에서 장애 아동을 대상 으로 다차원적이고 포괄적인 서비스 지원을 담당할 예비 전문 가인 대학생들에게 현장학습의 일환으로 장애인식개선 및 장 애인권교육 프로그램의 기획, 제작 및 진행 등의 전 과정에 교 육자로 참여할 수 있는 기회를 통하여 장애인에 대한 올바른 태도 정립을 유도하여 서비스 대상에 대한 이해를 높임으로써 전문가로서의 책임감을 가질 수 있도록 하였다. 연구 결과, 장 애인식개선 및 장애인권교육 프로그램에 대한 봉사활동이 대 학생의 장애수용태도에 긍정적인 효과가 있는 것으로 나타나 선행연구 결과와 일치한 결과로 본 연구는 단지 장애인식개선 및 장애인권교육 프로그램의 수동적 학습효과만을 밝힌 선행 연구에서 나아가 프로그램 교육자로서의 참여 효과를 밝혔다 는데 의의가 있다.

중심 단어 : 성취동기역량·융복합 수업·장애수용태도.

\section{REFERENCES}

Ahn, H. (2011). Effect of career education on self-efficacy and achievements motivation of vocational high school students (unpublished master's thesis). Myongji University, Seoul.

Cha, Y. K., Kim, S. A., Kim, S. J., Moon, J. E., Song, R. J., Park, Y. S., et al. (2014). Theory and practice of convergence education (pp. 17-29). Seoul: Hakjisa.

Choi, G. H. (2011). The effects of occupational types on attitudes toward people with disabilities. Journal of Vocational Rehabilitation, 20(3), 265-280.

Choi, S. K., Oh, W. S., Song, H, G., \& Ju, M. Y. (2008). A study on university students' attitudes towards the community living of intellectually disabled people. Journal of Mental Retardation, 10(1), 185-205.

Geum, Y. C. (2006). Industrial high school students' achievement motivation and factors related to educational environment. Journal of Employment and Skills Development, 9(1), 105-127.

Ham, S. H., Ku, H. R., Kim, S. A., Kim, S. J., Moon, J. E., Park, Y. S., et al. (2013). Conceptualizing yungbokhap education: An analysis of focus group interviews with school teachers. The Journal of Curriculum and Evaluation, 16(1), 107-136.

Hunt, B. \& Hunt, C. S. (2000). Attitudes toward people with disabilities: a comparison of undergraduate rehabilitation and business majors. Rehabilitation Research, Policy and Education, 14(3), 269-284.

Ju, M. K., Moon, J. E., \& Song R. J. (2012). Convergence education in mathematics: Issues and tasks. School Mathematics, 14(1), 165-190.

Jung, E. S. \& Cho, B. H. (2010). The effect of leadership development program on the leadership life skill and achievement motivation of ele- 
mentary school students. Journal of Evaluation on Counseling, 3(2), 1-14. Jung, M. B. (2010). Study on teacher's understanding of the disabled: Focused on SDA Sahmyook elementary, middle and high schools (unpublished master's thesis). Sahmyook University, Seoul.

Jung, M. G. (2011). Exploring an alternative direction of university dance curriculum in convergence education (unpublished doctor's dissertation). Sejong University, Seoul.

Kang, H. K. \& Park, E. (2006). Influence of the classroom-based language intervention on the communication of young children with disabilities: With collaboration between special education teacher and therapeutic education teacher. Korean Journal of Special Education, 41(2), 173-197.

Kim, B. S. (2015a). Development \& its effectiveness of "The Youth's Achieving Motivation Capability Program" (unpublished doctor's dissertation). Myongji University, Seoul.

Kim, H. R. (2006). Why do you wear hearing aids? Seoul: Aicorea.

Kim, J. H. (2008). The influence of learning motive program on the learned helplessness and self-efficacy of students in elementary school (unpublished master's thesis). Gyeongin National University of Education, Incheon.

Kim, S. A. (2014). The role and characteristics of art in convergence education: Based on the teacher FGI. Art Education Review, 51, 93-110.

Kim, Y. A. (2015b). A study on literature-based convergence education method: Focus on primary school education (unpublished doctor's dissertation). Hanyang University, Seoul.

Kim, Y. S., Baik H. W., Nam Y. H., Kim, S. Y., \& Kim, M. (2015). The factors on acceptable attitudes of health science college students toward people with disabilities. Korean Journal of Physical, Multiple, and Health Disabilities, 58(2), 185-201.
Ko, C. H. (2009). A study on university students' perception of disabilities for hearing-impaired persons in situations of personal and social relations (unpublished master's thesis). Daegu University, Gyeongsan.

Koo, S. M., Kim, J. S., \& Lim, D. H. (2006). A summary of the census for the disabled in Korea-focusing on the hearing impaired. Audiology, 2(1), 52-57.

Kwon, I. N. \& Kim, T. K. (2010). Development of measurement tool for youth activity competence. Youth Facilities and Environment, 8(4), 4561.

Lee, H. S. (2011). A study of non-disabled college students' perception and attitudes toward disabled college students (unpublished master's thesis). Korea Nazarene University, Cheonan.

Lee, S. H. (2007). A study on social welfare undergraduates' attitude toward the mentally Ill: Focusing on volunteer's experience at mental health facilities, educational experience of mental health-related course, and practical training at mental health facilities (unpublished master's thesis). Ewha Womans University, Seoul.

Park, M. R. (2015). The effect of mathematics-based yungbokhap instruction: An analysis of participation structure in small group (unpublished master's thesis). Hanyang University, Seoul.

Rideau, H. H. (1999). My ears don't match. Seoul: Woongjin Thinkbig.

Utley, B. L. \& Rapport, M. J. K. (2002). Essential elements of effective teamwork: Shared understanding and differences between special educators and related service providers. Physical Disabilities: Education and Related Services, 20(2), 9-47.

You, B. K. (2014). A qualitative case study on the implementation of convergence education in innovation middle school (unpublished doctor's dissertation). Hanyang University, Seoul. 